\title{
Withaferin A Induces Oxidative Stress-Mediated Apoptosis and DNA Damage in Oral Cancer Cells
}

\begin{abstract}
Hsueh-Wei Chang ${ }^{1,2,3,4,5}$, Ruei-Nian Li ${ }^{1}$, Hui-Ru Wang ${ }^{6}$, Jing-Ru Liu ${ }^{1}$, Jen-Yang Tang ${ }^{7,8,9}$, Hurng-Wern Huang ${ }^{6}$, Yu-Hsuan Chan ${ }^{1}$ and Ching-Yu Yen ${ }^{10,11 *}$

${ }^{1}$ Department of Biomedical Science and Environmental Biology, Kaohsiung Medical University, Kaohsiung, Taiwan, ${ }^{2}$ Department of Medical Research, Kaohsiung Medical University Hospital, Kaohsiung, Taiwan, ${ }^{3}$ Cancer Center, Kaohsiung Medical University Hospital; Kaohsiung Medical University, Kaohsiung, Taiwan, ${ }^{4}$ Research Center for Natural Products and Drug Development, Kaohsiung Medical University, Kaohsiung, Taiwan, ${ }^{5}$ Institute of Medical Science and Technology, National Sun Yat-Sen University, Kaohsiung, Taiwan, ${ }^{6}$ Institute of Biomedical Science, National Sun Yat-Sen University, Kaohsiung, Taiwan, ${ }^{7}$ Department of Radiation Oncology, Faculty of Medicine, College of Medicine, Kaohsiung Medical University, Kaohsiung, Taiwan, ${ }^{8}$ Department of Radiation Oncology, Kaohsiung Medical University Hospital, Kaohsiung, Taiwan, ${ }^{9}$ Department of Radiation Oncology, Kaohsiung Municipal Ta-Tung Hospital, Kaohsiung, Taiwan, ${ }^{10}$ Department of Oral and Maxillofacial Surgery Chi-Mei Medical Center, Tainan, Taiwan, " ${ }^{1}$ School of Dentistry, Taipei Medical University, Taipei, Taiwan
\end{abstract}

OPEN ACCESS

Edited by:

Gareth Davison,

Ulster University, United Kingdom

Reviewed by:

Vivek Choudhary,

Augusta University, United States

Paola Patrignani,

Università degli Studi "G. d'Annunzio"

Chieti-Pescara, Italy

Juan Antonio Rosado Dionisio,

University of Extremadura, Spain

*Correspondence:

Ching-Yu Yen

ycysmc@gmail.com

Specialty section

This article was submitted to

Oxidant Physiology,

a section of the journal

Frontiers in Physiology

Received: 23 February 2017

Accepted: 14 August 2017

Published: 07 September 2017

Citation:

Chang H-W, Li R-N, Wang H-R

$L i u J-R$, Tang J-Y, Huang H-W,

Chan Y-H and Yen C-Y (2017)

Withaferin A Induces Oxidative

Stress-Mediated Apoptosis and DNA

Damage in Oral Cancer Cells.

Front. Physiol. 8:634

doi: 10.3389/fphys.2017.00634
Withaferin A (WFA) is one of the most active steroidal lactones with reactive oxygen species (ROS) modulating effects against several types of cancer. ROS regulation involves selective killing. However, the anticancer and selective killing effects of WFA against oral cancer cells remain unclear. We evaluated whether the killing ability of WFA is selective, and we explored its mechanism against oral cancer cells. An MTS tetrazolium cell proliferation assay confirmed that WFA selectively killed two oral cancer cells (Ca9-22 and CAL 27) rather than normal oral cells (HGF-1). WFA also induced apoptosis of Ca9-22 cells, which was measured by flow cytometry for subG1 percentage, annexin $\vee$ expression, and pan-caspase activity, as well as western blotting for caspases 1, 8, and 9 activations. Flow cytometry analysis shows that WFA-treated Ca9-22 oral cancer cells induced G2/M cell cycle arrest, ROS production, mitochondrial membrane depolarization, and phosphorylated histone H2A.X $(\gamma \mathrm{H} 2 \mathrm{AX})$-based DNA damage. Moreover, pretreating Ca9-22 cells with $\mathrm{N}$-acetylcysteine (NAC) rescued WFA-induced selective killing, apoptosis, G2/M arrest, oxidative stress, and DNA damage. We conclude that WFA induced oxidative stress-mediated selective killing of oral cancer cells.

Keywords: oral cancer, selective killing, apoptosis, oxidative stress, withaferin $\mathrm{A}, \mathrm{N}$-acetylcysteine

\section{INTRODUCTION}

Most anticancer drugs effectively kill cancer cells; however, they also non-selectively kill normal cells, which limits their therapeutic value. It is currently believed that deregulated cell proliferation and deregulated apoptosis contributes to carcinogenesis (Reed, 1999). When the balance between proliferation and apoptosis is interrupted during tumor development, cell proliferation is deregulated (Scully et al., 2000; Evan and Vousden, 2001). Therapeutics that target oral squamous cell carcinoma (OSCC) cell proliferation and apoptosis regulators can enable these cancer cells to evade the regulatory system (Evan and Vousden, 2001). 
Reactive oxygen species (ROS) are primarily generated in the mitochondria, and they cause a loss of mitochondrial membrane potential (MMP) (Li et al., 2006; Oh and Lim, 2006). ROS is an important inducer for the early stages of apoptosis (SamhanArias et al., 2004) and DNA damage (Barzilai and Yamamoto, 2004; Chen et al., 2016). Several drugs that modulate ROS have been reported (Nicco et al., 2005; Trachootham et al., 2006; Wu and Hua, 2007; Widodo et al., 2010) to regulate apoptosis for selective killing. Thus, ROS might mediate the selective activation of apoptosis for selective killing in cancer chemotherapy (Pollack et al., 2001; Daniel et al., 2003; Real et al., 2004).

Recently, several natural products have also been reported to induce apoptosis involving ROS (Ding et al., 2009; Chiu et al., 2013; Lee et al., 2013; Vyas and Singh, 2014). For example, the antiproliferation effect of cancer cells for the natural product from Withania somnifera ( $W$. somnifera) is commonly reported to steroidal lactones (withanolides) (Vyas and Singh, 2014). Of the various withanolides derived from the root or leaf of $W$. somnifera, withaferin A (WFA) appears to be the most active against cancer (Vyas and Singh, 2014). The molecular anticancer activities of WFA have been reported through its antioxidant, anti-inflammatory and metabolic activities (Vanden Berghe et al., 2012; Vyas and Singh, 2014). WFA also induces ROS production and mitochondriamediated caspase activation in apoptosis of HL-60 myeloid leukemia cells (Malik et al., 2007). Thus, WFA has potential for modulating apoptosis and oxidative stress. Moreover, WFA has been widely used in several types of cancer (Malik et al., 2007; Uma Devi et al., 2008; Woo et al., 2014; Lee et al., 2015), but its use in oral cancer cells has not been sufficiently investigated.

We therefore hypothesized that WFA killed oral cancer cells by regulating oxidative stress-mediated apoptosis. We tested this hypothesis by evaluating cell viability, cell cycle changes, annexin $\mathrm{V}$, caspases, ROS, MMP, and DNA damage. Moreover, the role of oxidative stress in WFA-induced cell killing of oral cancer cells was examined by the addition of an antioxidant $N$-acetylcysteine (NAC). Therefore, this work sheds light on exploring the roles of oxidative stress-mediated WFA-induced cell killing mechanism of oral cancer cells.

\section{MATERIALS AND METHODS Cell Cultures and Chemicals}

Ca9-22 and CAL 27 oral cancer cell lines and HGF-1 normal human gingival fibroblast cell lines were kept in Dulbecco's Modified Eagle's Medium (DMEM) (Gibco, Grand Island, NY, USA) plus $10 \%$ fetal bovine serum (FBS) at $37^{\circ} \mathrm{C}$ in a humidified atmosphere containing $5 \% \mathrm{CO}_{2}$, as previously described (Chang Y. T. et al., 2016). WFA was purchased from Selleckchem.com (Houston, TX, USA) and dissolved in dimethyl sulfoxide (DMSO) for experiments. An antioxidant or free radical scavenger NAC (Sigma-Aldrich; St. Louis, MO, USA) was pretreated before WFA treatment to diminish cellular ROS and confirm the role of oxidative stress in WFA treatment.

\section{Cell Viability}

Cell viability was measured using an MTS assay (CellTiter 96 Aqueous One Solution; Promega, Madison, WI, USA), as previously described (Chiu et al., 2013).

\section{Cell Cycle Distribution}

DNA content was detected using 7-aminoactinomycin D (7AAD), a DNA dye, (Vignon et al., 2013). After fixation in 70\% ethanol, cells were treated with $1 \mu \mathrm{g} / \mathrm{ml} 7 \mathrm{AAD}$ for $30 \mathrm{~min}$ at $37^{\circ} \mathrm{C}$. Finally, the cells were resuspended in phosphate-buffered saline (PBS), and signals were examined using the FL3 channel of the Accuri C6 flow cytometer, and software (BD Biosciences, Franklin Lakes, New Jersey, USA). The G2/M percentage was calculated as the $\mathrm{G} 2 / \mathrm{M}$ population among the whole cell cycle phases (G1, S, and G2/M).

\section{Annexin V/DNA Content Assay to Measure Apoptosis}

Apoptosis was measured using annexin V/propidum iodide (PI) (Strong Biotech Corp., Taipei, Taiwan; and Sigma-Aldrich) or annexin V/7AAD, as previously described (Chiu et al., 2011). After cells were treated with the WFA- or NAC/WFA (NAC pretreatment and WFA posttreatment), they were treated for 30 min at $37^{\circ} \mathrm{C}$ with annexin $\mathrm{V}$-fluorescein isothiocyanate (annexin V-FITC) $(10 \mu \mathrm{g} / \mathrm{ml})$ and PI $(5 \mu \mathrm{g} / \mathrm{ml})$ or annexin V-FITC/7AAD $(1 \mu \mathrm{g} / \mathrm{ml})$, and then resuspended in PBS for analysis using the FL1/FL2 or FL1/FL3 channels of the Accuri C6 flow cytometer and software, respectively.

\section{Pan-caspase Assay to Measure Apoptosis}

Apoptosis was measured using a generic caspase activity assay kit (Fluorometric-Green: ab112130; Abcam, Cambridge, UK) (Yeh et al., 2012) for detecting the activity of caspases-1, 3-9. After the cells had been treated with WFA or NAC/WFA, they were treated with $2 \mu \mathrm{l}$ of 500X TF2-VAD-FMK per $2 \mathrm{ml}$ of medium for $2 \mathrm{~h}$ in a cell cultureincubator. After the cells had been washed with PBS, they were resuspended in $0.5 \mathrm{ml}$ of assay buffer, and signals were immediately detected using the FL1 channel of the Accuri C6.

\section{Western Blotting of Caspase Signaling to Measure Apoptosis}

The detailed procedures of western blotting are described previously (Chen et al., 2016). Briefly, $30 \mu \mathrm{g}$ of protein lysates was loaded for $10 \%$ SDS-PAGE (sodium dodecylsulfate polyacrylamide gel electrophoresis), and transferred to PVDF (polyvinylidene fluoride) membranes (Pall Corp., Port Washington, NY, USA). Protein blocking was done using 5\% non-fat milk in Tris-buffered saline with Tween-20. Subsequently, the lysates were treated with primary antibodies: cleaved caspase-8 (Asp391) (18C8) rabbit monoclonal antibody (mAb); cleaved PARP [poly(ADP-ribose) polymerase] (Asp214) (D64E10) $\mathrm{XP}^{\circledR}$ rabbit mAb; cleaved caspase-3 (Asp175) (5A1E) rabbit mAb; and cleaved caspase-9 (Asp330) (D2D4) rabbit mAb (Cell Signaling Technology, Inc., Danvers, MA, USA) (diluted 1:1000). mAb- $\beta$-actin (clone AC-15) (\#A5441; Sigma-Aldrich) (diluted 1:5,000) was used as a control. Their matched secondary antibodies were also used. Signal was detected using a substrate 
(WesternBright ${ }^{\mathrm{TM}}$ ECL HRP: \#K-12045-D50; Advansta, Menlo Park, CA, USA). The densitometry quantification of blot was determined by ImageJ freeware.

\section{ROS Production Assay}

$2^{\prime}, 7^{\prime}$-Dichlorodihydrofluorescein diacetate $\left(\mathrm{H}_{2} \mathrm{DCF}-\mathrm{DA}\right)$ was used for ROS detection, as previously described (Shih et al., 2014). After the cells were treated with WFA or NAC/WFA, they were treated with $100 \mathrm{nM}$ of $\mathrm{H}_{2}$ DCF-DA in PBS for $30 \mathrm{~min}$ in a cell culture incubator. After the cells were harvested and washed, they were resuspended in PBS and their signals were immediately analyzed using the FL1 channel of the Accuri C6.

\section{Mitochondrial Membrane Potential (MMP) Assay}

MMP was detected using an assay kit (MitoProbe ${ }^{\mathrm{TM}} 3,3^{\prime}$ diethyloxacarbocyanine iodide $\left(\mathrm{DiOC}_{2}(3)\right)$ (Invitrogen, San Diego, CA, USA)) as previously described (Yen et al., 2012). After the cells were treated with WFA or NAC/WFA, they were washed with PBS and treated with 10 of $10 \mu \mathrm{M} \mathrm{DiOC}{ }_{2}(3)$ per $1 \mathrm{ml}$ of medium/well in a 6-well plate in a cell culture incubator for 20$30 \mathrm{~min}$. After the cells were harvested and washed, they were resuspended in PBS and their signals were immediately analyzed using the FL1 channel of the Accuri C6.

\section{Phosphorylated Histone H2A.X ( $\gamma \mathrm{H} 2 \mathrm{AX})$ Assay}

$\gamma \mathrm{H} 2 \mathrm{AX}$, DNA double-strand break biomarker, was detected using flow cytometry as previously described (Chen et al., 2016). After the cells were treated with WFA or NAC/WFA, they were fixed with $70 \%$ ethanol. After they had been washed, they were treated with $2 \mu \mathrm{g} / \mathrm{ml}$ of phospho-Histone 2A.X (Ser139) Antibody (H2AX) (sc-101696; Santa Cruz Biotechnology, Santa Cruz, CA, USA) at $4^{\circ} \mathrm{C}$ for $1 \mathrm{~h}$. After the cells were washed, they were treated with a secondary antibody (Jackson Laboratory, Bar Harbor, ME, USA) at room temperature for $30 \mathrm{~min}$. Finally, the cells were treated in $20 \mu \mathrm{g} / \mathrm{ml}$ of PI, and their signals were detected using the FL1/FL2 channels of the Accuri C.

\section{Statistical Analysis}

All data are presented as means \pm SD. Each analysis was performed in three separate experiments at different times $(n=3)$. All data were analyzed using Student paired $t$-test of Sigmaplot 10.0 (Scientific Data Analysis and Graphing Software, Systat Software Inc., Chicago, IL, USA).

\section{RESULTS}

\section{The Viability of Oral Cancer Cells and Normal Oral Cells Treated with WFA Was Significantly Affected in WFA-Treated Cells with NAC Pretreatment}

MTS assays showed that the relative cell viability (\%) of the Ca922 and CAL 27 oral cancer cells were significantly lower than control after $24 \mathrm{~h}$ WFA treatments of $0.5,1,2$, and $3 \mu \mathrm{M}$ in a dose-dependent manner (Figure 1A). In contrast, HGF-1 normal oral cells treated with WFA showed no reduction in viability.

The involvement of oxidative stress in drug treatment is usually validated by pretreating cells with an antioxidant like NAC (Chan et al., 2006; Shieh et al., 2014; Hung et al., 2015; Lien et al., 2017). Cells treated with NAC-only [NAC pretreatment $(2 \mathrm{mM}) /$ WFA posttreatment $(0 \mu \mathrm{M})]$ differed non-significantly from untreated controls (no NAC pretreatment and no WFA posttreatment in all three types of cells (Figure 1B). Moreover, WFA-induced antiproliferation was significantly inhibited in two types of WFA-treated oral cancer cells with NAC pretreatment (NAC/WFA) $(p<0.05-0.001)$.

To further validate the low cytotoxicity of WFA-treated HGF1 normal oral cells, the levels of WFA-induced apoptosis in HGF-1 cells were evaluated using the pan-caspase assay. The flow cytometric pan-caspase patterns of WFA-treated HGF-1 cells are shown in Figure 1C. Generic caspase activities in WFAtreated HGF-1 cells slightly increased at 1-3 $\mu \mathrm{M}$ WFA about $60 \%$ compared to the control (50\%) ( $p<0.001)$ (Figure 1D), suggesting that WFA only induced minor signs of apoptosis (only $10 \%$ induction) with low cytotoxicity to HGF-1 normal oral cells compared to the control.

\section{Cell Cycle-Perturbed Distribution of CA9-22 Oral Cancer Cells Treated with WFA Was Inhibited in WFA-Treated Cells with NAC Pretreatment}

The flow cytometric cell cycle patterns of Ca9-22 oral cancer cells treated with WFA are shown in Figure 2A (top panel). Sub-G1 populations were higher in Ca9-22 cells treated with WFA than the control (Figure 2B, top panel). The flow cytometric cell cycle patterns of WFA and NAC/WFAtreated Ca9-22 cells are shown in Figure 2A (bottom panel). WFA-induced sub-G1 accumulation (Figure 2B, top panel) was significantly inhibited in WFA-treated Ca9-22 cells with NAC pretreatment (NAC/WFA) $(p<0.001)$. Moreover, G2/M populations were higher in Ca9-22 cells treated with WFA ranging from 1 to $2 \mu \mathrm{M}$ (Figure $2 \mathbf{B}$, bottom panel). WFAinduced G2/M accumulation (Figure 2B, bottom panel) was significantly inhibited in WFA $(2 \mu \mathrm{M})$-treated Ca9-22 cells with NAC pretreatment (NAC/WFA) $(p<0.05)$.

\section{Annexin V/PI-Induced Apoptosis of CA9-22 Oral Cancer Cells Treated with WFA Was Inhibited in WFA-Treated Cells with NAC Pretreatment}

The flow cytometric annexin V/PI patterns of Ca9-22 oral cancer cells treated with WFA are shown in Figure 3A. The annexin $\mathrm{V}$ positive $(+)$ expression (\%) for WFA-treated Ca9-22 cells was higher than the control in a dose-dependent manner (Figure 3B).

The flow cytometric annexin V/PI patterns of WFAand NAC/WFA-treated Ca9-22 cells are shown in Figure 3C. Annexin $\mathrm{V}(+)$ expression in cells treated with NAC differed nonsignificantly from those in untreated controls of WFA-treated Ca9-22 cells (Figure 3D, left). Moreover, WFA-induced annexin 

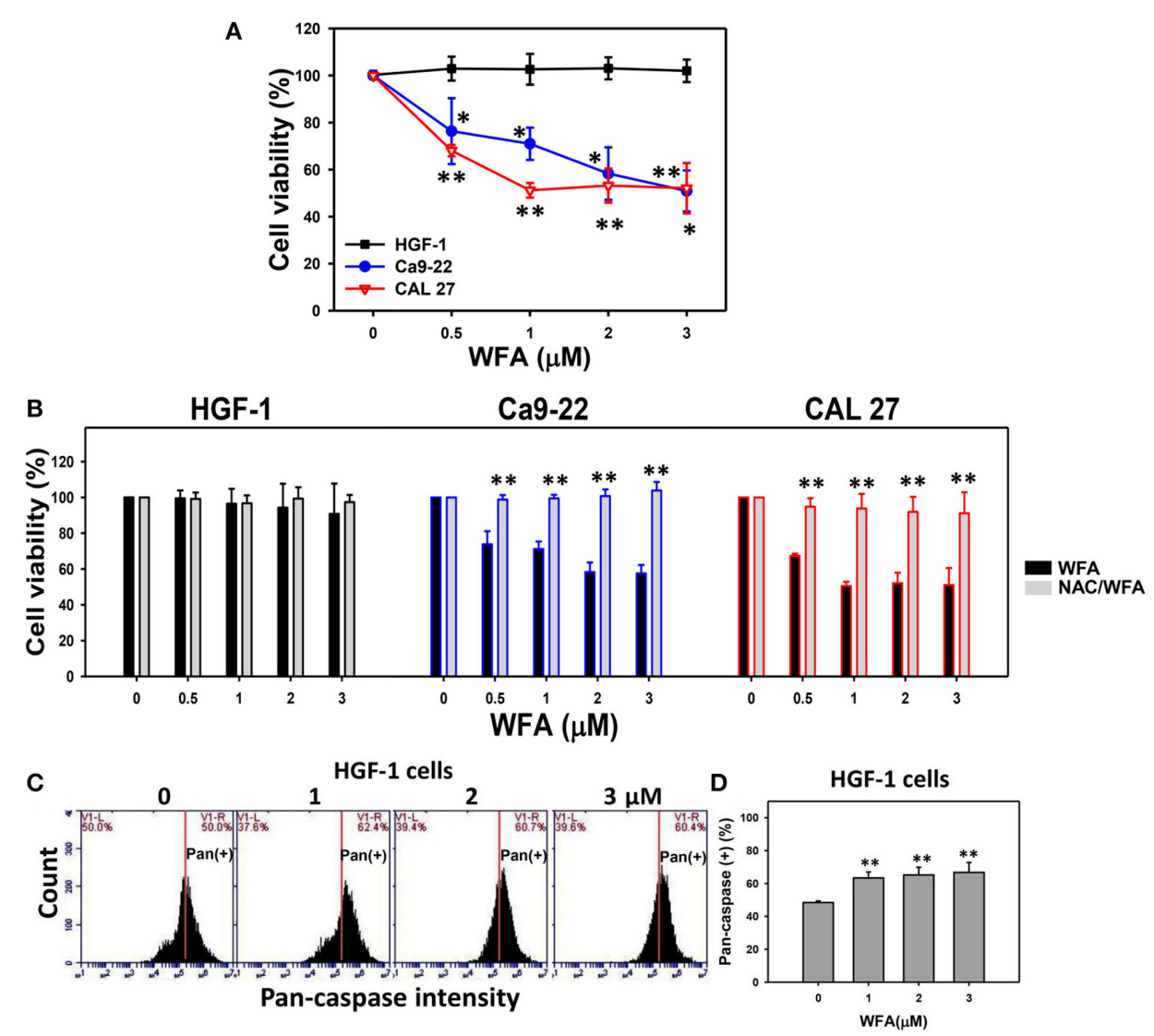

FIGURE 1 | MTS-based cell viability of WFA-treated oral cancer cells and normal cells and its changes after NAC pretreatment. (A) Oral cancer cells (Ca9-22 and CAL 27) and oral normal cells (HGF-1) were treated with WFA (0-3 $\mu$ M) for $24 \mathrm{~h}$. (B) NAC pretreatment effect on MTS-based cell viability of WFA-treated oral cancer and oral normal cells. Cells were pretreated with $2 \mathrm{mM}$ NAC for $1 \mathrm{~h}$ and post-treated with WFA $(0-3 \mu \mathrm{M})$ for $24 \mathrm{~h}$. (C) Typical patterns of pan-caspase activity for WFA-treated oral normal cells (HGF-1). Cells were treated with different concentrations $(0-3 \mu M)$ of WFA for $24 \mathrm{~h}$ for pan-caspase analysis. V1-L and V1-R listed in the corner of each plot, respectively, indicate the percentages of cell population (black color) on the left and right sides of the vertical line. In the control, the percentages of cell populations for V1-L and V1-R are 50\% each (Chang H. W. et al., 2016). The position of this line is at the same position for all treatments as the control setting. Positive (+) \%, the cell population on the right side of the line, is indicated in each (D) Pan-caspase-based apoptosis (+) (\%) for (C). Data are means \pm SDs $(n=3)$. $(\mathbf{A}, \mathbf{D}){ }^{*} p<0.05$ and ${ }^{* *} p<0.001$ against control $(0 \mu \mathrm{M})$. (B) ${ }^{* *} p<0.001$ for comparison between WFA and NACMFA (NAC pretreatment and WFA posttreatment).

V-based apoptosis was significantly inhibited in WFA-treated Ca9-22 cells with NAC pretreatment (NAC/WFA) (Figure 3D, right) $(p<0.001)$.

\section{Pan-caspase-Based Apoptosis of CA9-22 Oral Cancer Cells Treated with WFA Was Inhibited in WFA-Treated Cells with NAC Pretreatment}

The involvement of caspases in the apoptosis of WFA-treated Ca9-22 cells was examined using a TF2-VAD-FMK flow cytometric assay (Figure 4). The flow cytometric pan-caspase patterns of WFA-treated Ca9-22 cells are shown in Figure 4A. Generic caspase activities in Ca9-22 cells treated with WFA ranging from 2 to $3 \mu \mathrm{M}$ showed a significant increase above $80 \%$ compared to the control $(50 \%)(p<0.05-0.001)$, i.e., $30 \%$ induction (Figure 4B). The flow cytometric pan-caspase patterns of WFA- and NAC/WFA-treated Ca9-22 cells are provided in Figure 4C. In Figure 4D, the WFA-induced pan-caspasebased apoptosis in Ca9-22 cells was significantly inhibited in
WFA-treated Ca9-22 cells with NAC pretreatment (NAC/WFA) $(p<0.05)$.

The involvement of caspases in the change of pan-caspase activity was validated using western blotting. In Figures $4 E, F$, the expression of apoptosis signaling proteins, such as cleaved PARP and cleaved-caspases 3, 8, and 9, was higher in WFA-treated Ca922 cells; although some of them declined at a concentration of $3 \mu \mathrm{M}$. In contrast, these caspase signaling proteins of the WFAtreated Ca9-22 cells were inhibited in WFA-treated Ca9-22 cells with NAC pretreatment (NAC/WFA).

\section{ROS Generated Oxidative Stress of CA9-22 Oral Cancer Cells Treated with WFA Was Inhibited in WFA-Treated Cells with NAC Pretreatment}

The ROS positive $(+)$ patterns of WFA-treated Ca9-22 cells for 3,6 , and $12 \mathrm{~h}$ are displayed in Figure 5A. The ROS (+) (\%) expression of WFA-treated Ca9-22 cells was significantly and time-dependently higher $(p<0.001)$ (Figure 5B). 


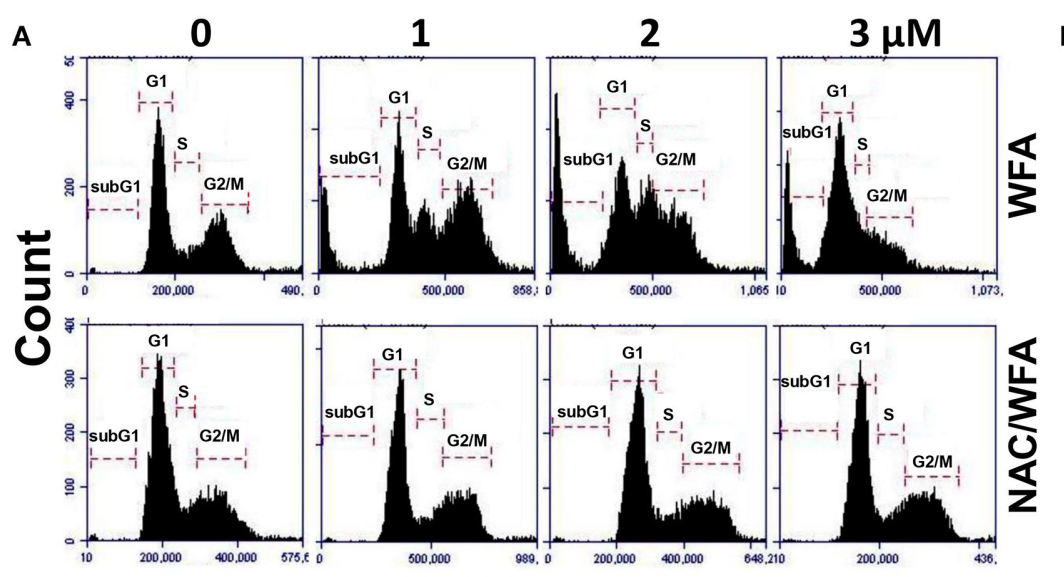

DNA content
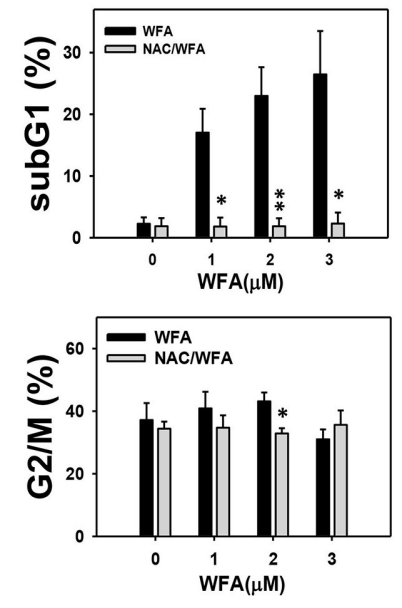

FIGURE 2 | The cell cycle distribution of WFA-treated Ca9-22 oral cancer cells and its changes after NAC pretreatment. (A) Typical cell cycle patterns of WFA-treated Ca9-22 oral cancer cells with and without NAC pretreatment. With and without NAC pretreatment ( 2 mM NAC for $1 \mathrm{~h})$, cells were post-treated with WFA (0-3 $\mu$ M) for 24 h. (B) SubG1 and G2/M phases (\%) for (A). Data are means \pm SDs $(n=3) .{ }^{*} p<0.05$ and ${ }^{* *} p<0.001$ for comparison between WFA and NAC/WFA for each concentration of WFA. NACMFA, NAC pretreatment and WFA posttreatment.
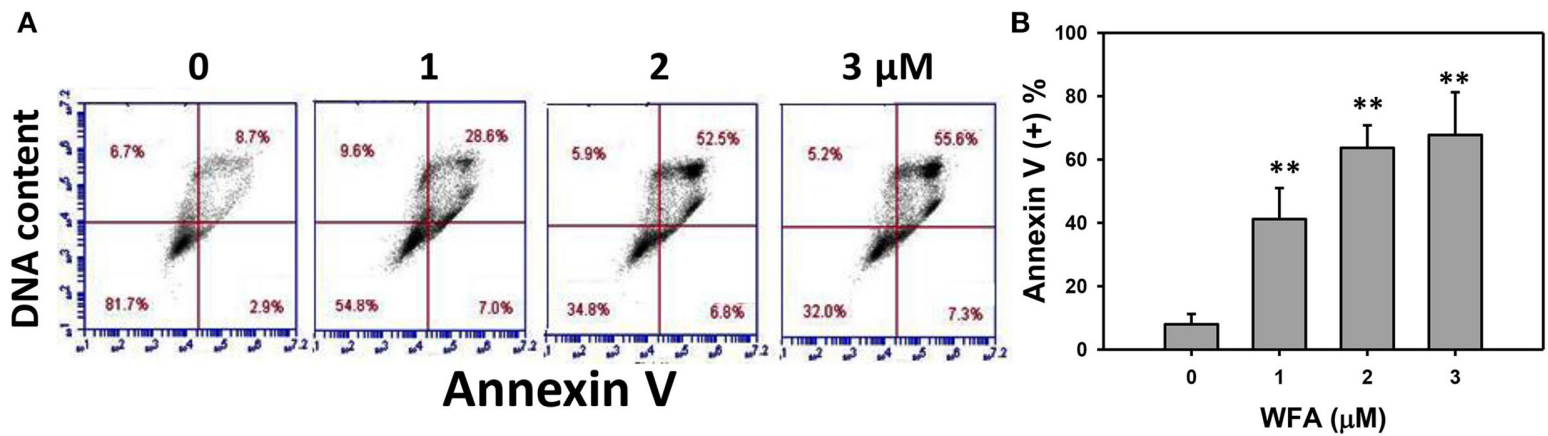

C

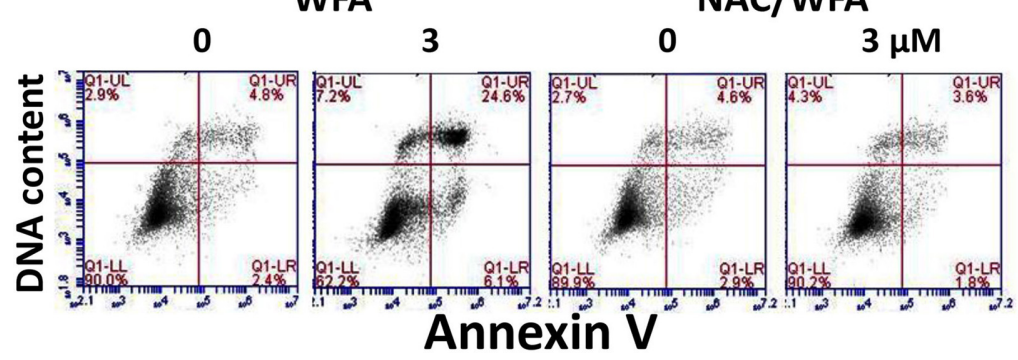

D

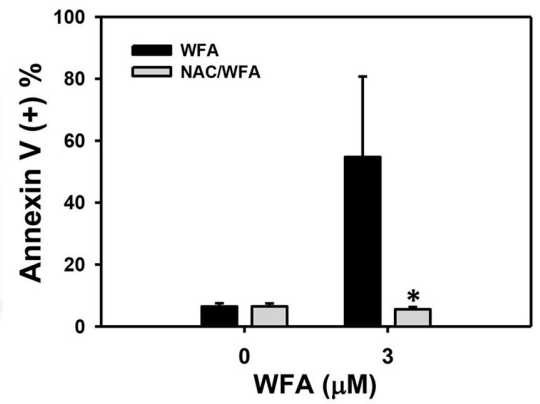

FIGURE 3 | Apoptosis of WFA-treated Ca9-22 oral cancer cells and its changes after NAC pretreatment. (A) Typical patterns of annexin V/DNA content method for WFA-treated Ca9-22 oral cancer cells. Cells were treated with WFA (0-3 $\mu \mathrm{M})$ of $24 \mathrm{~h}$ for flow cytometry analyses. (B) Annexin $\vee$ positive (+) (\%) for (A). (C) Typical annexin/DNA content-based apoptosis patterns of NAC effect on WFA-treated Ca9-22 cells. With or without NAC pretreatment (2 mM NAC for 1 h), cells were post-treated with WFA $(0$ and $3 \mu \mathrm{M})$ for $24 \mathrm{~h}$. (D) Annexin/DNA content-based apoptosis (+) (\%) for (C). Data are means \pm SDs $(n=3)$. (B) ${ }^{* *} p<0.001$ against control $(0 \mu \mathrm{M})$. (D) ${ }^{*} p<0.05$ for comparison between WFA and NAC/WFA (NAC pretreatment and WFA posttreatment).

Figure 5C shows the ROS (+) patterns of WFA- and NAC/WFA-treated Ca9-22 cells at $24 \mathrm{~h}$ of WFA treatment. Figure 5D shows higher ROS $(+)$ expression in Ca9-22 cells after WFA treatment when compared to the control in a dose-dependent manner. ROS production induced by WFA treatment was significantly inhibited in WFA-treated Ca922 cells with NAC pretreatment (NAC/WFA) (Figure 5D) $(p<0.001)$. 

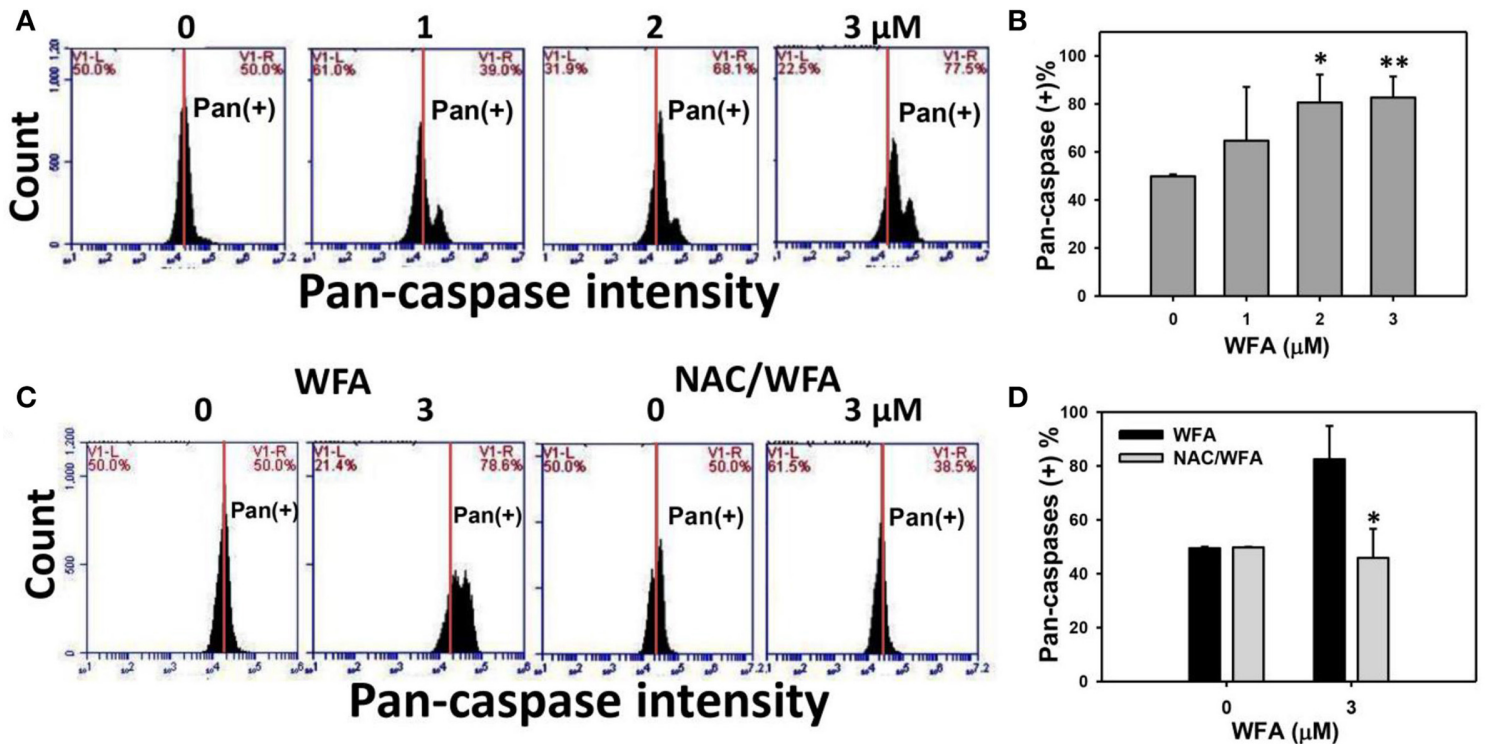

E

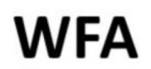

$\begin{array}{llll}0 & 1 & 2 & 3\end{array} \mu \mathrm{M}$

0

NAC/WFA

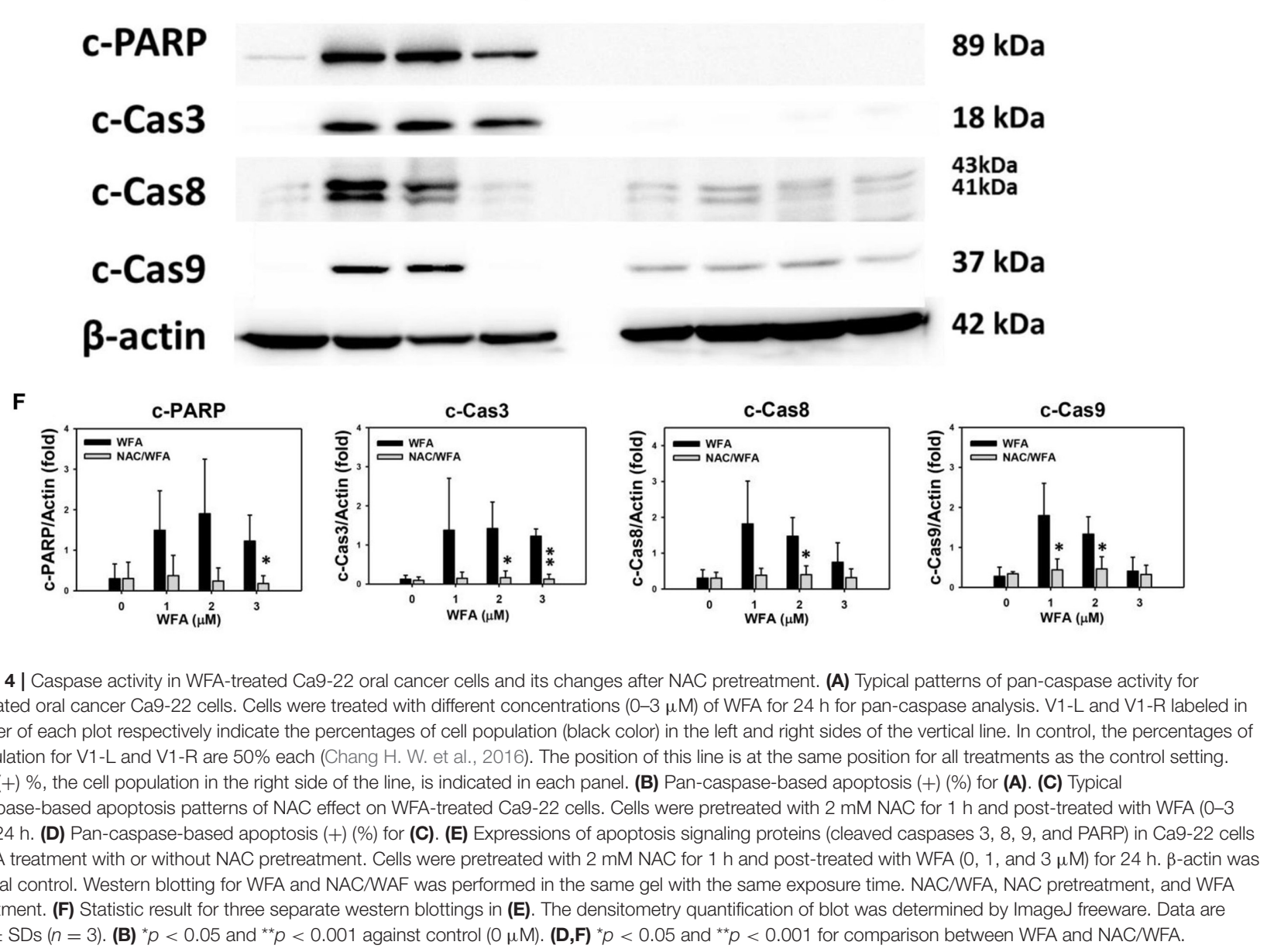



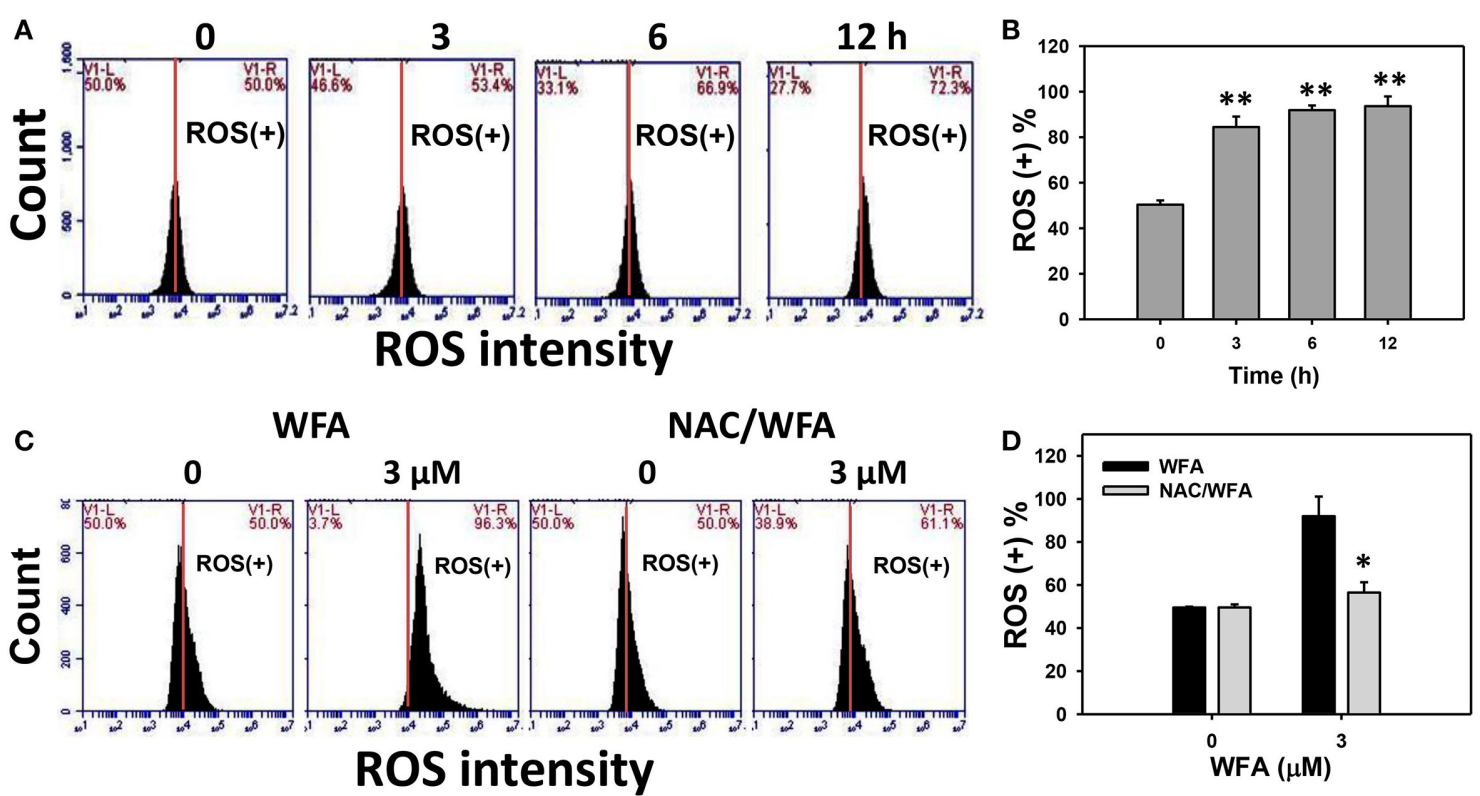

FIGURE 5 | ROS levels of WFA-treated Ca9-22 oral cancer cells and its changes after NAC pretreatment. (A) Typical ROS patterns of WFA-treated Ca9-22 oral cancer cells. Cells were treated with WFA $(0-3 \mu \mathrm{M})$ for 3,6 , and $12 \mathrm{~h}$ for flow cytometry analysis. V1-L and V1-R labeled in the corner of each plot respectively indicate the percentages of cell population (black color) in the left and right sides of the vertical line. In the control, the percentages of cell populations for V1-L, and V1-R are 50\% each (Chang H. W. et al., 2016). The position of this line is at the same position for all treatments as the control setting. Positive (+) \%, the cell population in the right side of the line, is indicated in each panel. (B) ROS (+) intensity (\%) for (A). (C) Typical ROS patterns of NAC effect on WFA-treated Ca9-22 cells. Cells were pretreated with $2 \mathrm{mM} \mathrm{NAC}$ for $1 \mathrm{~h}$ and post-treated with WFA (0-3 $\mu \mathrm{M})$ for (24 h). (D) ROS (+) intensity (\%) for (C). NAC/WFA, NAC pretreatment and WFA posttreatment. Data are means \pm SDs $(n=3)$. (B) ${ }^{\star *} p<0.001$ against control $(0 \mu \mathrm{M})$. (D) ${ }^{*} p<0.05$ for comparison between WFA and NAC/WFA for each concentration of WFA.

\section{Mitochondrial Membrane Potential (MMP) of CA9-22 Oral Cancer Cells Treated with WFA Was Inhibited in WFA-Treated Cells with NAC Pretreatment}

The MMP negative (-) expression (\%) of WFA-treated Ca9-22 is displayed in Figure 6A. After Ca9-22 cells were treated with WFA for $24 \mathrm{~h}$, the MMP (-) expression (\%) of WFA-treated Ca922 cells were increased (Figure 6B), suggesting that WFA induces mitochondrial membrane depolarization in Ca9-22 cells.

The flow cytometric MMP patterns of WFA- and NAC/WFAtreated Ca9-22 cells are displayed in Figure 6C. WFA-induced increase of MMP (-) expression was significantly inhibited in WFA-treated Ca9-22 cells with NAC pretreatment (NAC/WFA) $(p<0.001)$ (Figure 6D).

\section{$\gamma \mathrm{H} 2 \mathrm{AX}-\mathrm{Based}$ DNA Damage of CA9-22 Oral Cancer Cells Treated with WFA Was Inhibited in WFA-Treated Cells with NAC Pretreatment}

$\gamma \mathrm{H} 2 \mathrm{AX}$ was flow cytometrically measured the DNA damage in WFA-treated Ca9-22 oral cancer cells. The percentages and profiles of $\gamma \mathrm{H} 2 \mathrm{AX}$ positive (+) stained cells were shown for the $24 \mathrm{~h}$ treatments with $0,1,2$, and $3 \mu \mathrm{M}$ of WFA (Figure 7A). After $24 \mathrm{~h}$ of WFA treatment, the \% of $\gamma \mathrm{H} 2 \mathrm{AX}(+)$ stained cells was significantly higher than the control $(p<0.05-0.001)$ (Figure 7B).
The flow-cytometry $\gamma \mathrm{H} 2 \mathrm{AX}$ patterns of WFA- and NAC/WFA-treated Ca9-22 cells were provided in Figure 7C. WFA-induced $\gamma \mathrm{H} 2 \mathrm{AX}$ expression was significantly inhibited in WFA-treated Ca9-22 cells with NAC pretreatment (NAC/WFA) $(p<0.05)$ (Figure 7D).

\section{DISCUSSION}

WFA has anticancer (Uma Devi et al., 2008; Woo et al., 2014; Lee et al., 2015) and ROS production (Lee et al., 2009; Li et al., 2017; Liu et al., 2017) effects in several types of cancer. However, the selective killing effect of WFA was rarely investigated as yet, especially in oral cancer cells. The aim of this study is to examine the selective killing effects of WFA against oral cancer cells and to explore the role of oxidative stress in WFA-treated oral cancer cells. The cell killing, apoptosis, cell cycle, DNA damage, and oxidative stress effects of WFA in oral cancer cells are discussed as follows.

\section{Comparison of $\mathrm{IC}_{50}$ Using WFA in Different Types of Cancer Cells}

Different cancer cell types are sensitive to WFA. For example, the $\mathrm{IC}_{50}$ values of WFA were $2 \mu \mathrm{M}$ for myeloid leukemia (HL60) cells (24 h; MTT assay) (Malik et al., 2007), about $2 \mu \mathrm{M}$ for pancreatic cancer cells (Panc-1 and MIAPaCa-2) (48 h; MTS assay) ( $\mathrm{Li}$ et al., 2015), and 0.2-1.2 $\mu \mathrm{M}$ for cervical cancer cells (C33a, CaSki, HeLa, and SiHa) (24 h; MTT assay) (Munagala 

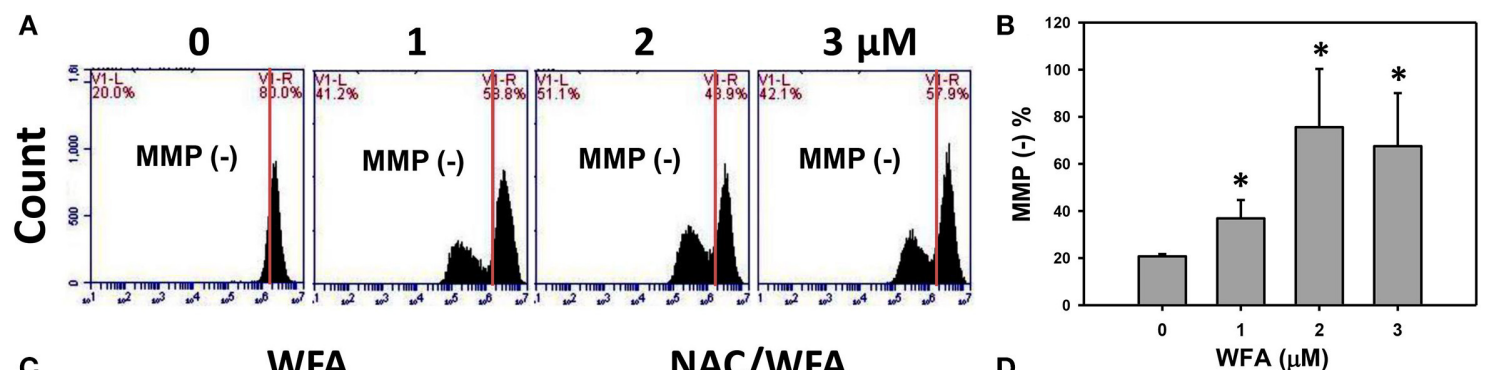

C

WFA

NAC/WFA
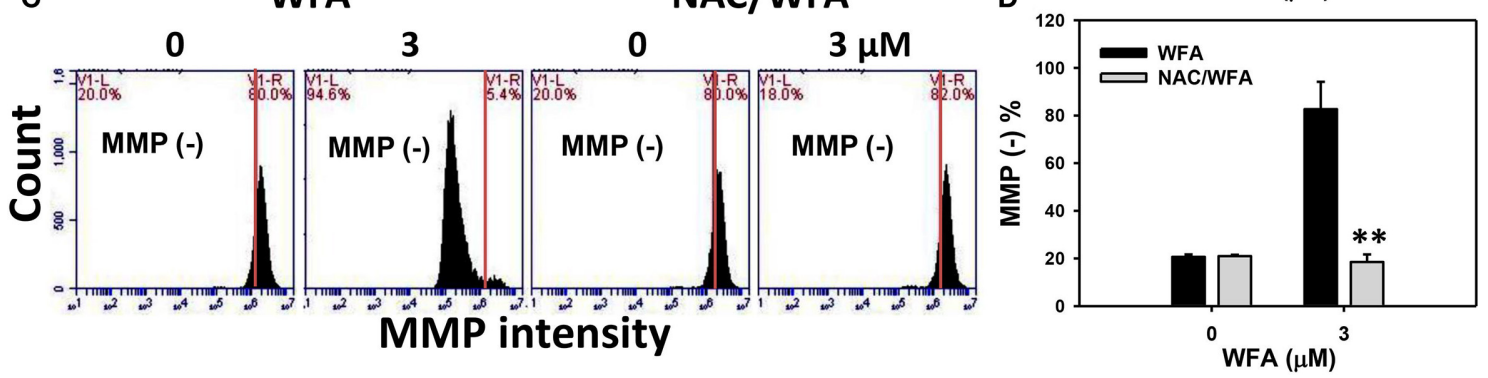

FIGURE 6 | MMP levels of WFA-treated Ca9-22 oral cancer cells and its changes after NAC pretreatment. (A) Typical MMP patterns of WFA-treated Ca9-22 oral cancer cells. Cells were treated with WFA $(0-3 \mu \mathrm{M})$ for $24 \mathrm{~h}$ for flow cytometry analysis. V1-L and V1-R labeled in the corner of each plot respectively indicate the percentages of cell populations (black color) in the left and right sides of the vertical line. In control, the percentages of cell populations for V1-L and V1-R are 20 and $80 \%$, respectively (Chang H. W. et al., 2016). The position of this line is at the same position for all treatments as the control setting. MMP-negative (-) (\%), the cell population in the left side of the line, is indicated in each panel. (B) MMP (-) intensity (\%) for (A). (C) Typical MMP patterns of the effect of NAC on WFA-treated Ca9-22 cells. Cells were pretreated with $2 \mathrm{mM}$ NAC for $1 \mathrm{~h}$ and post-treated with WFA (0-3 $\mu$ M) for $24 \mathrm{~h}$. (D) MMP $(-)(\%)$ for (C). Data are means \pm SDs $(n=3)$.

(B) ${ }^{\star} p<0.05$ against control $(0 \mu \mathrm{M})$. (D) ${ }^{\star *} p<0.001$ for comparison between WFA and NAC/WFA (NAC pretreatment and WFA posttreatment).
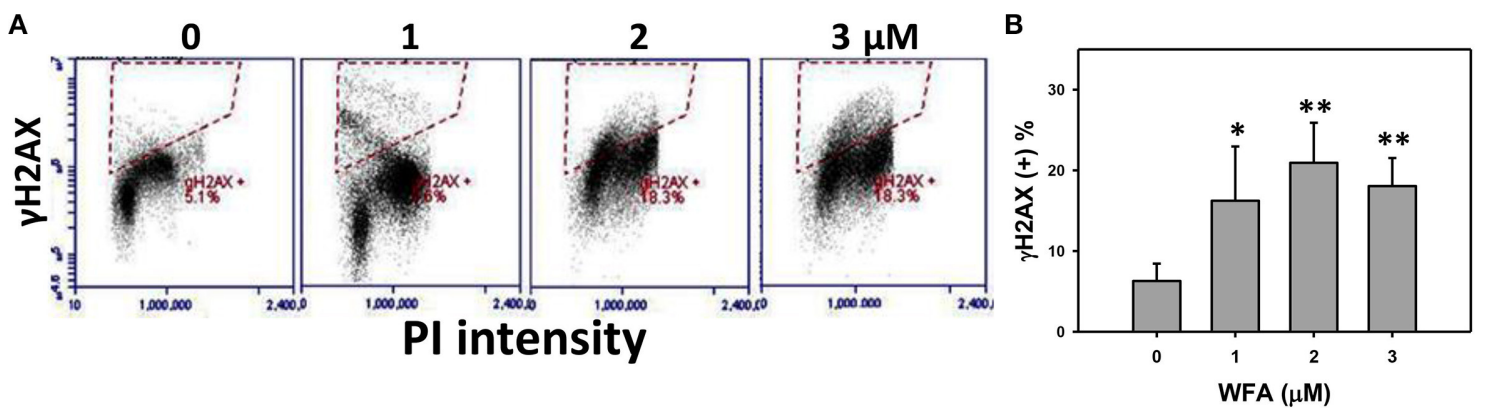

C

WFA

NAC/WFA
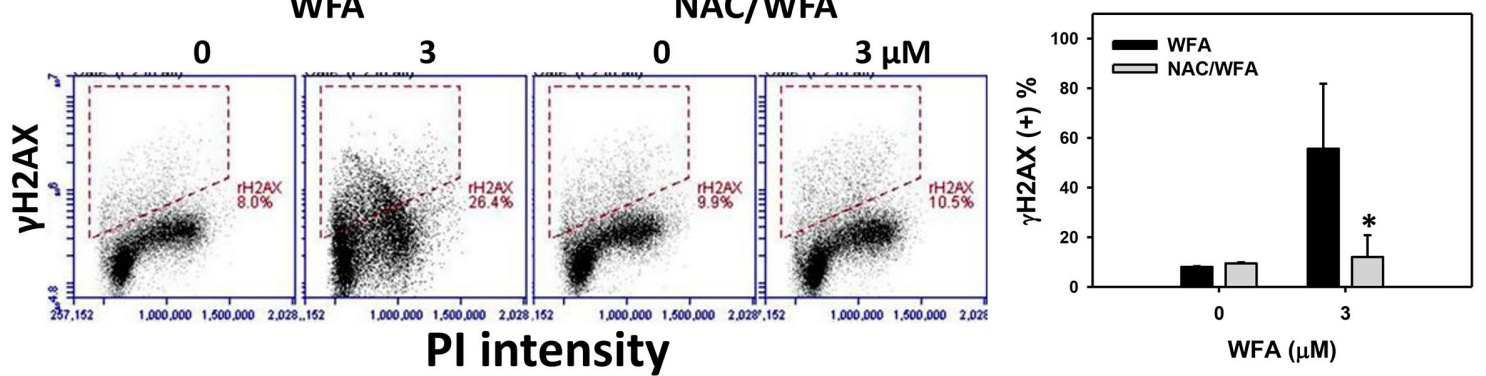

FIGURE 7 | DNA double strand breaks of WFA-treated Ca9-22 oral cancer cells and its changes after NAC pretreatment. (A) Ca9-22 oral cancer cells treated with different concentrations (0-3 $\mu \mathrm{M}$ ) of WFA for $24 \mathrm{~h}$ were stained with $\gamma \mathrm{H} 2 \mathrm{AX}$. (B) $\gamma \mathrm{H} 2 \mathrm{AX}$ positive $(+)$ intensity (\%) for (A). (C) Typical DNA damage patterns of NAC effect on WFA-treated Ca9-22 cells. Cells were pretreated with 2 mM NAC for $1 \mathrm{~h}$ and post-treated with WFA (0-3 $\mu$ M) for $12 \mathrm{~h}$. (D) $\gamma \mathrm{H} 2 \mathrm{AX}(+)$ intensity (\%) for (C) Data are means \pm SDs $(n=3)$. (B) ${ }^{*} p<0.05$ and ${ }^{* *} p<0.001$ against control $(0 \mu \mathrm{M})$. (D) ${ }^{*} p<0.05$ for comparison between WFA and NAC/WFA (NAC pretreatment and WFA posttreatment). 
et al., 2011). However, the selective killing effect of WFA was not thoroughly investigated in these studies. We also found that the $\mathrm{IC}_{50}$-values of WFA in Ca9-22 and CAL 27 oral cancer cells were 3 and $2 \mu \mathrm{M}$ (24 h; MTS assay), respectively. In contrast, WFA did not harm HGF-1 normal oral cells. Accordingly, WFA induces selective killing against oral cancer cells without adverse effects for the viability of normal oral cells. Therefore, we provide here the first report that documents WFA's selective killing effects against oral cancer cells.

However, HGF-1 normal human gingival cells are a type of fibroblast cell lines and oral cancer cells arise from the epithelium. It was reported that some epithelial and fibroblast cells had different responses to various signaling molecules. For example, epithelial cells undergo growth arrest in response to TGF- $\beta$, whereas fibroblasts undergo morphological changes, and proliferate (Wilkes et al., 2003). Therefore, the possibility of selective killing of WFA against oral cancer cells warrants further detailed investigation. In a follow-up study we will compare oral cancer cells with normal epithelial cells using a similar experimental design.

\section{WFA Induces Apoptosis in Cancer Cells}

In the current study, WFA induced apoptosis in Ca9-22 oral cancer cells associated with subG1 accumulation and caspase activation. This is consistent with the findings that WFA induced apoptosis in CaSki cervical cancer cells (Munagala et al., 2011) and WFA induced apoptosis in MDA-MB-231 and MCF-7 breast cancer cells (Hahm and Singh, 2013). In the current study (Figure 4E), the cleaved caspases (3, 8, and 9) and cleaved PARP showed high cleavage (high apoptosis) in 1 and $2 \mu \mathrm{M}$ of WFA, but showed less cleavage (less apoptosis) in $3 \mu \mathrm{M}$ of WFA. Similarly, other drugs have related findings. For example, etoposide induced more cleavage of PARP at 2 and 4 days, but declined at day 6 in human non-small cell lung cancer cells (H1437) (Chiu et al., 2005). Ganciclovir induced more cleavage of PARP, caspases 3/9, and cytochrome $c$ at 1 or 2 days, but declined at 3 days in human non-small cell lung cancer cells (CL-1) (Chiu et al., 2002). It is possible that higher dose treatment or longer exposure may lead to more cell death and fail to proportionally cleave apoptotic proteins. Furthermore, caspase-1 may mediate apoptosis (Bergsbaken et al., 2009; Miao et al., 2011; Sollberger et al., 2014) and it warrants further investigation for the role of caspase-1 in WFA induced apoptosis.

In addition to the induction of subG1 accumulation, WFA induces $\mathrm{G} 2 / \mathrm{M}$ arrest and a mitotic catastrophe in prostate cancer cells in terms of cell cycle analysis and western blotting for several G2/M arresting proteins (Roy et al., 2013). WFA also induces G2/M arrest in gastric cancer cells (Kim et al., 2017), osteosarcoma cells (Lv and Wang, 2015), and breast cancer cells (Zhang et al., 2011). Similar to the current study, WFA induced G2/M arrest in Ca9-22 cells at lower concentrations (1 and $2 \mu \mathrm{M})$ but did not present at higher concentration $(3 \mu \mathrm{M})$ (Figure 2B) where subG1 population (apoptosis) was gradually increased.

\section{WFA Induces DNA Damage in Cancer Cells}

Drug-induced ROS generation is associated with DNA damage (Yang et al., 2012; Chiu et al., 2013; Chen et al., 2016). Since
WFA is known to induce ROS production (Lee et al., 2009; Li et al., 2017; Liu et al., 2017) (Figure 5), the DNA damage effect warrants for investigation. In the current study, we found that WFA treatment induced $\gamma \mathrm{H} 2 \mathrm{AX}$ expression in Ca9-22 oral cancer cells, which is consistent with the findings that WFAinduced $\gamma \mathrm{H} 2 \mathrm{AX}$ expression in MCF7 breast cancer cells, but not in normal human TIG-3 fibroblasts (Widodo et al., 2010). This DNA damaging ability was shown to be associated with apoptosis in several other cancer cell studies (Norbury and Zhivotovsky, 2004; Roos and Kaina, 2006).

\section{WFA-Induced Cell Killing, Apoptosis, Cell Cycle Change, and DNA Damage Are Medidated by Oxidative Stress in Cancer Cells}

NAC is a common free radical scavenger. NAC pretreatment is reported to effectively diminish cellular ROS and to confirm the role of oxidative stress in drug treatment. Recently, several WFA-based cancer therapies were reported to be rescued by NAC pretreatment. For example, WFA induced apoptosis in human melanoma cells was accomplished by generating ROS (Mayola et al., 2011), and NAC pretreatment rescued ROS-induced damage. NAC also inhibited WFA-induced ROS production and caspase activation of human HL-60 myeloid leukemia cells (Malik et al., 2007).

Similarly, we found that NAC pretreatment rescued WFAinduced apoptosis in Ca9-22 oral cancer cells by subG1 accumulation, annexin V/PI, pan-caspases, and caspase signaling in western blotting. In our study, low concentration of WFA-induced G2/M arrest in Ca9-22 cells was rescued by NAC pretreatment. NAC pretreatment rescued WFA-induced oxidative stress in Ca9-22 cells by ROS and MMP analysis. NAC pretreatment also rescued $\gamma \mathrm{H} 2 \mathrm{AX}$-based DNA damage in Ca9-22 cells as shown by the flow cytometry assay. This is the first evidence that NAC pretreatment protects WFA-treated oral cancer cells against oxidative stress.

\section{CONCLUSION}

WFA selectively killed oral cancer cells with less toxic effects to normal oral cells. WFA also induced apoptosis, oxidative stress, and DNA damage, which ultimately inhibited the proliferation of oral cancer cells.

\section{AUTHOR CONTRIBUTIONS}

JL, HW, and YC carried out the experiments. JT and $\mathrm{HH}$ analyzed the data. HC, RL, and CY conceived and designed the study. HC and $\mathrm{CY}$ wrote and revised the manuscript.

\section{ACKNOWLEDGMENTS}

This work was partly supported by grants: MOST 104-2320B-037-013-MY3 and MOST 105-2314-B-037-036 from the Ministry of Science and Technology; 106CM-KMU-05 from the Chimei-KMU Joint Project; NSYSUKMU 106-P001 from the 
National Sun Yat-Sen University-KMU Joint Research Project; KMUH105-5R61 from the Kaohsiung Medical University Hospital; and MOHW106-TDU-B-212-144007 from the Taiwan

\section{REFERENCES}

Barzilai, A., and Yamamoto, K. (2004). DNA damage responses to oxidative stress. DNA Repair 3, 1109-1115. doi: 10.1016/j.dnarep.2004.03.002

Bergsbaken, T., Fink, S. L., and Cookson, B. T. (2009). Pyroptosis: host cell death and inflammation. Nat. Rev. Microbiol. 7, 99-109. doi: 10.1038/nrmicro2070

Chan, W. H., Shiao, N. H., and Lu, P. Z. (2006). CdSe quantum dots induce apoptosis in human neuroblastoma cells via mitochondrial-dependent pathways and inhibition of survival signals. Toxicol. Lett. 167, 191-200. doi: 10.1016/j.toxlet.2006.09.007

Chang, H. W., Tang, J. Y., Yen, C. Y., Chang, H. S., Huang, H. W., Chung, Y. A., et al. (2016). Synergistic anti-oral cancer effects of UVC and methanolic extracts of Cryptocarya concinna roots via apoptosis, oxidative stress and DNA damage. Int. J. Radiat. Biol. 92, 263-272. doi: 10.3109/09553002.2016.1145753

Chang, Y. T., Huang, C. Y., Li, K. T., Li, R. N., Liaw, C. C., Wu, S. H., et al. (2016). Sinuleptolide inhibits proliferation of oral cancer Ca9-22 cells involving apoptosis, oxidative stress, and DNA damage. Arch. Oral Biol. 66, 147-154. doi: 10.1016/j.archoralbio.2016.02.019

Chen, C. Y., Yen, C. Y., Wang, H. R., Yang, H. P., Tang, J. Y., Huang, H. W., et al. (2016). Tenuifolide B from Cinnamomum tenuifolium stem selectively inhibits proliferation of oral cancer cells via apoptosis, ROS generation, mitochondrial depolarization, and DNA damage. Toxins 8:319. doi: 10.3390/toxins8110319

Chiu, C. C., Haung, J. W., Chang, F. R., Huang, K. J., Huang, H. M., Huang, H. W., et al. (2013). Golden berry-derived $4 \beta$-hydroxywithanolide E for selectively killing oral cancer cells by generating, ROS DNA damage, and apoptotic pathways. PLoS ONE 8:e64739. doi: 10.1371/journal.pone.0064739

Chiu, C. C., Kang, Y. L., Yang, T. H., Huang, C. H., and Fang, K. (2002). Ectopic expression of herpes simplex virus-thymidine kinase gene in human nonsmall cell lung cancer cells conferred caspase-activated apoptosis sensitized by ganciclovir. Int. J. Cancer 102, 328-333. doi: 10.1002/ijc.10701

Chiu, C. C., Li, C. H., Ung, M. W., Fuh, T. S., Chen, W. L., and Fang, K. (2005). Etoposide (VP-16) elicits apoptosis following prolonged G2-M cell arrest in p53-mutated human non-small cell lung cancer cells. Cancer Lett. 223, 249-258. doi: 10.1016/j.canlet.2004.10.049

Chiu, C. C., Liu, P. L., Huang, K. J., Wang, H. M., Chang, K. F., Chou, C. K., et al. (2011). Goniothalamin inhibits growth of human lung cancer cells through DNA damage, apoptosis, and reduced migration ability. J. Agric. Food Chem. 59, 4288-4293. doi: 10.1021/jf200566a

Daniel, D., Susal, C., Kopp, B., Opelz, G., and Terness, P. (2003). Apoptosismediated selective killing of malignant cells by cardiac steroids: maintenance of cytotoxicity and loss of cardiac activity of chemically modified derivatives. Int. Immunopharmacol. 3, 1791-1801. doi: 10.1016/j.intimp.2003. 08.004

Ding, H., Han, C., Guo, D., Chin, Y. W., Ding, Y., Kinghorn, A. D., et al. (2009). Selective induction of apoptosis of human oral cancer cell lines by avocado extracts via a ROS mediated mechanism. Nutr. Cancer 61, 348-356. doi: $10.1080 / 01635580802567158$

Evan, G. I., and Vousden, K. H. (2001). Proliferation, cell cycle and apoptosis in cancer. Nature 411, 342-348. doi: 10.1038/35077213

Hahm, E. R., and Singh, S. V. (2013). Withaferin A induced apoptosis in human breast cancer cells is associated with suppression of inhibitor of apoptosis family protein expression. Cancer Lett. 334, 101-108. doi: 10.1016/j.canlet.2012.08.026

Hung, J. H., Chen, C. Y., Omar, H. A., Huang, K. Y., Tsao, C. C., Chiu, C. C., et al. (2015). Reactive oxygen species mediate Terbufos-induced apoptosis in mouse testicular cell lines via the modulation of cell cycle and pro-apoptotic proteins. Environ. Toxicol. 31, 1888-1898. doi: 10.1002/tox.22190

Kim, G., Kim, T.-H., Hwang, E.-H., Chang, K.-T., Hong, J.-J., and Park, J.-H. (2017). Withaferin A inhibits the proliferation of gastric cancer cells by inducing G2/M cell cycle arrest and apoptosis. Oncol. Lett. 14, 416-422. doi: 10.3892/ol.2017.6169

Lee, J. C., Hou, M. F., Huang, H. W., Chang, F. R., Yeh, C. C., Tang, J. Y., et al. (2013). Marine algal natural products with anti-oxidative,
Ministry of Health and Welfare surcharge on tobacco products. The authors thank Dr. Hans-Uwe Dahms and Paula Bejar for English editing.

anti-inflammatory, and anti-cancer properties. Cancer Cell Int. 13:55. doi: 10.1186/1475-2867-13-55

Lee, J., Hahm, E. R., Marcus, A. I., and Singh, S. V. (2015). Withaferin A inhibits experimental epithelial-mesenchymal transition in MCF10A cells and suppresses vimentin protein level in vivo in breast tumors. Mol. Carcinog. 54, 417-429. doi: 10.1002/mc.22110

Lee, T. J., Um, H. J., Min do, S., Park, J. W., Choi, K. S., and Kwon, T. K., et al. (2009). induced apoptosis through reactive oxygen species-mediated upregulation of death receptor 5 and down-regulation of c-FLIP. Free Radic. Biol. Med. 46, 1639-1649. doi: 10.1016/j.freeradbiomed.2009.03.022

Li, A. X., Sun, M., and Li, X. (2017). Withaferin-A induces apoptosis in osteosarcoma U2OS cell line via generation of ROS and disruption of mitochondrial membrane potential. Eur. Rev. Med. Pharmacol. Sci. 21, 1368-1374. Available online at: http://www.europeanreview.org/ wp/wp-content/uploads/1368-1374-Withaferin-A-induces-apoptosis-inosteosarcoma-U2OS-cell-line.pdf

Li, J. J., Tang, Q., Li, Y., Hu, B. R., Ming, Z. Y., Fu, Q., et al. (2006). Role of oxidative stress in the apoptosis of hepatocellular carcinoma induced by combination of arsenic trioxide and ascorbic acid. Acta Pharmacol. Sin. 27, 1078-1084. doi: 10.1111/j.1745-7254.2006.00345.x

Li, X., Zhu, F., Jiang, J., Sun, C., Wang, X., Shen, M., et al. (2015). Synergistic antitumor activity of withaferin A combined with oxaliplatin triggers reactive oxygen species-mediated inactivation of the PI3K/AKT pathway in human pancreatic cancer cells. Cancer Lett. 357, 219-230. doi: 10.1016/j.canlet.2014.11.026

Lien, J. C., Lin, M. W., Chang, S. J., Lai, K. C., Huang, A. C., Yu, F. S., et al. (2017). Tetrandrine induces programmed cell death in human oral cancer CAL27 cells through the reactive oxygen species production and caspasedependent pathways and associated with beclin-1-induced cell autophagy. Environ. Toxicol. 32, 329-343. doi: 10.1002/tox.22238

Liu, X., Chen, L., Liang, T., Tian, X. D., Liu, Y., and Zhang, T., et al. (2017). Withaferin induces mitochondrial-dependent apoptosis in non-small cell lung cancer cells via generation of reactive oxygen species. J. BUON 22, 244-250. Available online at: https://www.jbuon.com/pdfs/244-250.pdf

Lv, T. Z., and Wang, G. S. (2015). Antiproliferation potential of withaferin A on human osteosarcoma cells via the inhibition of G2/M checkpoint proteins. Exp. Ther. Med. 10, 323-329. doi: 10.3892/etm.2015.2480

Malik, F., Kumar, A., Bhushan, S., Khan, S., Bhatia, A., Suri, K. A., et al. (2007). Reactive oxygen species generation and mitochondrial dysfunction in the apoptotic cell death of human myeloid leukemia HL-60 cells by a dietary compound withaferin A with concomitant protection by $\mathrm{N}$-acetyl cysteine. Apoptosis 12, 2115-2133. doi: 10.1007/s10495-007-0129-x

Mayola, E., Gallerne, C., Esposti, D. D., Martel, C., Pervaiz, S., Larue, L., et al. (2011). Withaferin A induces apoptosis in human melanoma cells through generation of reactive oxygen species and down-regulation of Bcl-2. Apoptosis 16, 1014-1027. doi: 10.1007/s10495-011-0625-x

Miao, E. A., Rajan, J. V., and Aderem, A. (2011). Caspase-1-induced pyroptotic cell death. Immunol. Rev. 243, 206-214. doi: 10.1111/j.1600-065X.2011 01044.x

Munagala, R., Kausar, H., Munjal, C., and Gupta, R. C. (2011). Withaferin A induces p53-dependent apoptosis by repression of HPV oncogenes and upregulation of tumor suppressor proteins in human cervical cancer cells. Carcinogenesis 32, 1697-1705. doi: 10.1093/carcin/bgr192

Nicco, C., Laurent, A., Chereau, C., Weill, B., and Batteux, F. (2005). Differential modulation of normal and tumor cell proliferation by reactive oxygen species. Biomed. Pharmacother. 59, 169-174. doi: 10.1016/j.biopha.2005.03.009

Norbury, C. J., and Zhivotovsky, B. D. N. A. (2004). Damage-induced apoptosis. Oncogene 23, 2797-2808. doi: 10.1038/sj.onc.1207532

Oh, S. H., and Lim, S. C. A. (2006). Rapid and transient ROS generation by cadmium triggers apoptosis via caspase-dependent pathway in HepG2 cells and this is inhibited through $\mathrm{N}$-acetylcysteine-mediated catalase upregulation. Toxicol. Appl. Pharmacol. 212, 212-223. doi: 10.1016/j.taap.2005. 07.018 
Pollack, I. F., Erff, M., and Ashkenazi, A. (2001). Direct stimulation of apoptotic signaling by soluble Apo2l/tumor necrosis factor-related apoptosisinducing ligand leads to selective killing of glioma cells. Clin. Cancer Res. 7, 1362-1369. Available online at: http://clincancerres.aacrjournals.org/content/ 7/5/1362.full-text.pdf

Real, P. J., Cao, Y., Wang, R., Nikolovska-Coleska, Z., Sanz-Ortiz, J., Wang, S., et al. (2004). Breast cancer cells can evade apoptosis-mediated selective killing by a novel small molecule inhibitor of Bcl-2. Cancer Res. 64, 7947-7953. doi: 10.1158/0008-5472.CAN-04-0945

Reed, J. C. (1999). Mechanisms of apoptosis avoidance in cancer. Curr. Opin. Oncol. 11, 68-75. doi: 10.1097/00001622-199901000-00014

Roos, W. P., and Kaina, B. D. N. A. (2006). Damage-induced cell death by apoptosis. Trends Mol. Med. 12, 440-450. doi: 10.1016/j.molmed.2006.07.007

Roy, R. V., Suman, S., Das, T. P., Luevano, J. E., Damodaran, C., and Withaferin, A. (2013). A steroidal lactone from Withania somnifera, induces mitotic catastrophe and growth arrest in prostate cancer cells. J. Nat. Prod. 76, 1909-1915. doi: 10.1021/np400441f

Samhan-Arias, A. K., Martin-Romero, F. J., and Gutierrez-Merino, C. (2004). Kaempferol blocks oxidative stress in cerebellar granule cells and reveals a key role for reactive oxygen species production at the plasma membrane in the commitment to apoptosis. Free Radic. Biol. Med. 37, 48-61. doi: 10.1016/j.freeradbiomed.2004.04.002

Scully, C., Field, J. K., and Tanzawa, H. (2000). Genetic aberrations in oral or head and neck squamous cell carcinoma (SCCHN): 1. Carcinogen metabolism, DNA repair and cell cycle control. Oral Oncol. 36, 256-263. doi: 10.1016/S1368-8375(00)00007-5

Shieh, J. M., Shen, C. J., Chang, W. C., Cheng, H. C., Chan, Y. Y., Huang, W. C., et al. (2014). An increase in reactive oxygen species by deregulation of ARNT enhances chemotherapeutic drug-induced cancer cell death. PLoS ONE 9:e99242. doi: 10.1371/journal.pone.0099242

Shih, H. C., El-Shazly, M., Juan, Y. S., Chang, C. Y., Su, J. H., Chen, Y. C., et al. (2014). Cracking the cytotoxicity code: apoptotic induction of 10acetylirciformonin B is mediated through ROS generation and mitochondrial dysfunction. Mar. Drugs 12, 3072-3090. doi: 10.3390/md12053072

Sollberger, G., Strittmatter, G. E., Garstkiewicz, M., Sand, J., and Beer, H. D. (2014). Caspase-1: the inflammasome and beyond. Innate Immun. 20, 115-125. doi: $10.1177 / 1753425913484374$

Trachootham, D., Zhou, Y., Zhang, H., Demizu, Y., Chen, Z., Pelicano, H., et al. (2006). Selective killing of oncogenically transformed cells through a ROS mediated mechanism by beta-phenylethyl isothiocyanate. Cancer Cell 10, 241-252. doi: 10.1016/j.ccr.2006.08.009

Uma Devi, P., Utsumiz, H., Takata, M., and Takeda, S. (2008). Enhancement of radiation induced cell death in chicken B lymphocytes by withaferin A. Indian J. Exp. Biol. 46, 437-442. Available online at: http://nopr.niscair.res.in/bitstream/ 123456789/4497/1/IJEB\%2046(6)\%20437-442.pdf

Vanden Berghe, W., Sabbe, L., Kaileh, M., Haegeman, G., and Heyninck, K. (2012). Molecular insight in the multifunctional activities of Withaferin A. Biochem. Pharmacol. 84, 1282-1291. doi: 10.1016/j.bcp.2012.08.027

Vignon, C., Debeissat, C., Georget, M. T., Bouscary, D., Gyan, E., Rosset, P., et al. (2013). Flow cytometric quantification of all phases of the cell cycle and apoptosis in a two-color fluorescence plot. PLOS ONE 8:e68425. doi: 10.1371/journal.pone.0068425

Vyas, A. R., and Singh, S. V. (2014). Molecular targets and mechanisms of cancer prevention and treatment by withaferin A, a naturally occurring steroidal lactone. AAPS J. 16, 1-10. doi: 10.1208/s12248-013-9531-1

Widodo, N., Priyandoko, D., Shah, N., Wadhwa, R., and Kaul, S. C. (2010). Selective killing of cancer cells by Ashwagandha leaf extract and its component Withanone involves ROS signaling. PLoS ONE 5:e13536. doi: 10.1371/journal.pone.0013536

Wilkes, M. C., Murphy, S. J., Garamszegi, N., and Leof, E. B. (2003). Cell-type-specific activation of PAK2 by transforming growth factor beta independent of Smad2 and Smad3. Mol. Cell Biol. 23, 8878-8889. doi: 10.1128/MCB.23.23.8878-8889.2003

Woo, S. M., Min, K. J., Kim, S., Park, J. W., Kim, D. E., Kim, S. H., et al. (2014). Axl is a novel target of withaferin A in the induction of apoptosis and the suppression of invasion. Biochem. Biophys. Res. Commun. 451, 455-460. doi: $10.1016 /$ j.bbrc.2014.08.018

Wu, X. J., and Hua, X. (2007). Targeting ROS selective killing of cancer cells by a cruciferous vegetable derived pro-oxidant compound. Cancer Biol Ther. 6, 646-647. doi: 10.4161/cbt.6.5.4092

Yang, J. I., Yeh, C. C., Lee, J. C., Yi, S. C., Huang, H. W., Tseng, C. N., et al. (2012). Aqueous extracts of the edible Gracilaria tenuistipitata are protective against $\mathrm{H}_{2} \mathrm{O}_{2}$-induced DNA damage, growth inhibition, and cell cycle arrest. Molecules 17, 7241-7254. doi: 10.3390/molecules170 67241

Yeh, C. C., Tseng, C. N., Yang, J. I., Huang, H. W., Fang, Y., Tang, J. Y., et al. (2012). Antiproliferation and induction of apoptosis in Ca9-22 oral cancer cells by ethanolic extract of Gracilaria tenuistipitata. Molecules 17, 10916-10927. doi: 10.3390/molecules170910916

Yen, C. Y., Chiu, C. C., Haung, R. W., Yeh, C. C., Huang, K. J., Chang, K. F., et al. (2012). Antiproliferative effects of goniothalamin on Ca9-22 oral cancer cells through apoptosis, DNA damage and ROS induction. Mutat. Res. 747, 253-258. doi: 10.1016/j.mrgentox.2012.06.003

Zhang, X., Mukerji, R., Samadi, A. K., and Cohen, M. S. (2011). Down-regulation of estrogen receptor-alpha and rearranged during transfection tyrosine kinase is associated with withaferin A-induced apoptosis in MCF-7 breast cancer cells. BMC Complement. Altern. Med. 11:84. doi: 10.1186/1472-688211-84

Conflict of Interest Statement: The authors declare that the research was conducted in the absence of any commercial or financial relationships that could be construed as a potential conflict of interest.

Copyright (c) 2017 Chang, Li, Wang, Liu, Tang, Huang, Chan and Yen. This is an open-access article distributed under the terms of the Creative Commons Attribution License (CC BY). The use, distribution or reproduction in other forums is permitted, provided the original author(s) or licensor are credited and that the original publication in this journal is cited, in accordance with accepted academic practice. No use, distribution or reproduction is permitted which does not comply with these terms. 